\title{
Efeito da posição do punho no controle de preensão em pinça de adultos jovens
}

\author{
Vanessa Luzia Barros de Andrade ${ }^{\mathrm{a}}$, Marcela de Castro Ferracioli ${ }^{\mathrm{a}}$, Cynthia Yukiko Hiraga ${ }^{\mathrm{b}}$, \\ Adriane Guzman Pascullia, Ana Maria Pellegrini ${ }^{\mathrm{b}}$
}

aUniversidade Estadual Paulista - UNESP, Rio Claro, SP, Brasil.

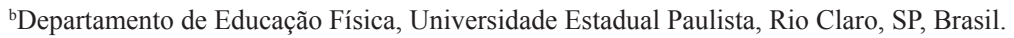

\begin{abstract}
Resumo: A preensão em pinça responde por um grande número de atividades manipulativas que requerem precisão e controle de um objeto. A posição das articulações do membro superior influencia a produção de força dos dedos para manipular um objeto. O objetivo do presente estudo foi verificar a influência da posição do punho na produção de força máxima e no controle de força submáxima na preensão em pinça pelos dedos. Participaram do estudo 21 adultos destros (10 homens, 18-26 anos). Os participantes realizaram duas tentativas de produção de força máxima e oito tentativas de produção de força submáxima (quatro de $20 \%$ e quatro de $40 \%$ da força máxima) na tarefa de preensão em pinça, em três posições da articulação do punho: neutra, flexão e extensão. Os resultados mostraram que a produção de força máxima é maior na posição neutra do que nas posições de extensão e flexão do punho, e maior para homens do que para mulheres. Além disso, houve correlação positiva entre comprimento da mão e produção de força máxima. Os resultados também mostraram que a posição do punho não interfere no controle de força submáxima nesta tarefa. No entanto, os participantes apresentaram mais dificuldade em controlar $20 \%$ do que $40 \%$ da força máxima. O presente estudo trouxe evidências de que as unidades motoras utilizadas para produzir força máxima de preensão em pinça cruzam a articulação do punho, mas aquelas utilizadas para controle de $20 \%$ e $40 \%$ da força máxima estão presentes apenas nos dedos e mão.
\end{abstract}

Palavras-chave: Punho, Preensão em Pinça, Força Máxima, Níveis de Força.

\section{Effect of wrist position on young adults pinch grip control}

\begin{abstract}
Pinch grip is used in a large number of handling activities that require precision and control of an object. The position of the upper arm joints affects the fingers force production in order to handle the object. This study aimed to verify the influence of the wrist position in the production of maximum strength and in the control fingers grip pinch submaximum strength control. Participants were 21 right handed adults (10 male, 18-26 years old). They made two attempts of maximum force production and eight attempts of submaximal force production (four at $20 \%$ and four at $40 \%$ of maximum strength) for pinch grip in three wrist positions: neutral, flexion and extension. The results showed that the production of maximum strength is higher in neutral position compared to wrist flexion and extension and higher for men compared to women. In addition, there was a positive correlation between the length of the hand and the production of maximum strength. The results also indicated that the wrist position did not interfere in the submaximum force control during this task. However, participants showed more difficulty controlling $20 \%$ than $40 \%$ of maximum strength. The present study showed evidence that the motor units used to produce grip pinch maximum strength cross the wrist joint but those used for the $20 \%$ and $40 \%$ of maximum strength are present only in the fingers and hand.
\end{abstract}

Keywords: Wrist, Grip Prehension, Maximum Strength, Strength Levels. Autor para correspondência: Marcela de Castro Ferracioli, Universidade Estadual Paulista, Avenida 24 A, 1515, Bela Vista, CEP 13506-900,
Rio Claro, SP, Brasil, e-mail: mcf@rc.unesp.br

Recebido em Ago. 9, 2014; $1^{\text {a }}$ Revisão em Set. 17, 2014; Aceito em Set. 24, 2014 


\section{Introdução}

A mão humana apresenta um bom número de capacidades para executar tarefas simples do dia a dia, como pressionar uma tecla ou manipular os talheres para comer, escrever, bem como tarefas complexas, como digitar, tocar piano, violáo, ou dirigir um carro. Uma característica funcional marcante da mão é segurar e manipular objetos através de uma aproximação entre a forma do objeto e a forma com que a mão naturalmente faz esta aproximação, para posterior produção de movimentos de flexáo e de extensão, como, por exemplo, para tocar piano, violáo, bateria, jogar tênis de mesa, bolinha de gude. A essa função, dá-se o nome de preensão (NEWELL et al., 1989).

As possíveis combinaçóes de dedos utilizadas para preensão de objetos são fundamentais para a independência no desempenho de tarefas diárias (FULLER; TROMBLY, 1997). Uma das combinaçôes mais importantes para a interação entre o indivíduo e o ambiente é a preensão em pinça, executada entre o dedo indicador e o polegar (LAMOREAUX; HOFFER, 1997). Esse formato de preensão se dá pelo deslocamento do polegar, a partir da sua posição neutra (polegar em abdução), na direção ulnar, com movimentos de flexão e rotação (ARAÚJO et al., 2002). O dedo indicador completa o movimento, flexionando todas as suas articulaçóes até entrar em contato com a superfície polpuda do polegar (NAPIER, 1983).

A preensão, particularmente a em pinça, pode ser executada com diferentes configuraçóes das articulaçóes do braço (punho, cotovelo e ombro), tendo em vista que a mobilidade e a estabilidade das mesmas, operando em planos e eixos diversos, possibilitam à mão se movimentar em grande alcance, com relativa facilidade (ARAÚJO et al., 2002). Estudos têm apontado a articulação do punho como a mais importante na tarefa de preensão em pinça (FRANKEL; NORDIN, 2003), já que as forças são geradas, principalmente, pela atividade dos músculos que compóem o complexo articular da mão, que são mais fracos, porém mais precisos, quando comparados, por exemplo, com músculos do ombro ou do cotovelo (ARAÚJO et al., 2002; MATSUSHITA et al., 1995). Além disso, tendo em vista que o movimento de extensão do punho facilita a flexão dos dedos por causa do encurtamento dos músculos flexores, e o movimento de flexáo do punho facilita a extensão dos dedos fornecendo alongamento aos flexores (FELDMAN, 1999), o movimento da articulaçáo do punho é determinante no controle da preensão pelos dedos. Tendo em vista estas características, a preensão em pinça é amplamente estudada sob o ponto de vista de controle motor.

A literatura aponta duas variáveis relevantes comumente consideradas na capacidade funcional da preensão em pinça: (i) produção de força máxima dos dedos e (ii) produção e manutenção de força submáxima dos dedos. A produção de força máxima corresponde ao máximo de força que um indivíduo é capaz de gerar com os dedos para prender um objeto durante um período de tempo (JOSTY et al., 1997). Já o controle de produção de força submáxima dos dedos corresponde ao ajustamento da magnitude das forças individuais e da distribuição de força entre os dedos, para manipulação ou estabilização de um determinado objeto entre os mesmos (FREITAS; KRISHNAN; JARIC, 2008; LIMA; FRANCISCO; FREITAS, 2012; ZATSIORSKY; LI; LATASH, 2000).

A posição das articulações do membro superior é outra variável importante para a produçáo de força dos dedos. Estudos têm mostrado que posiçóes extremas de flexão e extensão do punho diminuem a produção de força máxima dos dedos em tarefas de pressão com a palma da mão (CAREY; GALLWEY, 2002) e preensão em pinça (IMRHAN, 1991; LI, 2002), quando comparadas com a posição neutra. De acordo com os autores, isso ocorre porque, em posiçóes extremas do punho, pode haver encurtamento e alongamento da musculatura dos dedos, o que prejudica a produção de força máxima pelos mesmos, podendo levar a desordens de esforço repetitivo. Lamoreaux e Hoffer (1997) sugerem ainda que a posição do punho mais apropriada e segura para a produção de força máxima dos dedos é a de extensão moderada com ligeiro desvio ulnal. Um exemplo disso se encontra no estudo de Mogk e Keir (2003), em que dez indivíduos executaram tarefas de preensão manual, em três combinações de posições de punho (neutra, flexão e extensão) e em três posturas de antebraço (neutra, pronação e supinação). Os autores mostraram que, na posição de flexão do punho, a produção de força máxima diminui em pronação e supinação do antebraço, em comparação com as demais posiçóes, apesar de a atividade eletromiográfica dos músculos flexores dos dedos permanecer elevada.

A posição do punho, portanto, tem fundamental relação com a capacidade de produção de força máxima da mão e dos dedos. No entanto, não encontramos evidências empíricas de que posiçôes de flexão e/ou extensão extremas do punho também influenciam o controle da produção de força submáxima dos dedos. Neste sentido, se faz necessário ampliar estudos sobre a relação punho-mão, para podermos 
prevenir doenças e melhorar a condição de pessoas que já convivem com patologias na articulação em questão. Diante do exposto, o objetivo do presente estudo foi verificar o efeito da posição do punho (flexão, extensão e neutra) no controle da produção de força submáxima dos dedos de preensão isométrica em pinça polpa a polpa, entre os dedos polegar e indicador. Em complemento, tendo em vista que a produção de força máxima em tarefa de preensão tem sido correlacionada de modo significativo com o peso corporal, com o comprimento e com a espessura da mão (CAPORRINO et al., 1998; DEMPSEY; AYOUB, 1996; NICOLAY; WALKER, 2005), o presente estudo buscou verificar a influência de fatores antropométricos, como peso corporal e comprimento da mão, na produção de força máxima e no controle de produção de força submáxima nesta tarefa.

\section{Método}

\subsection{Participantes}

Participaram do estudo 21 adultos jovens destros, sendo 10 homens e 11 mulheres, com idade entre 18 e 26 anos (21,4 $\pm 2,4$ anos), sem histórico de traumas ou neuropatias no membro superior. Inicialmente, todos os participantes receberam informação sobre o objetivo e os procedimentos do estudo, e então assinaram o Termo de Consentimento Livre e Esclarecido. Os procedimentos relacionados à participação no estudo foram aprovados pelo Comitê de Ética em Pesquisa do Instituto de Biociências da UNESP - Rio Claro-SP, Protocolo 2100, 2008.

\subsection{Materiais}

Para identificação da preferência manual, foi utilizado o Inventário de Preferência Manual de Edinburgh (OLDFIELD, 1971). A estatura e o peso corporal dos participantes foram aferidos através de uma balança Welmy, modelo R-110. O comprimento da mão direita de cada participante foi mensurado com um paquímetro Cescorf $(50 \mathrm{~cm})$.
Para a execução das tarefas de preensão digital em pinça, foi utilizada uma célula de carga construída em metal (liga de alumínio AL 7075T6) com dimensóes de $100 \mathrm{~mm} \times 7 \mathrm{~mm} \times 25 \mathrm{~mm}$, instrumentada com extensômetros de resistência elétrica (strain gauges). Esta célula foi fixada e suspensa por uma presilha a um pedestal de ferro adaptado, de altura ajustável (Figura 1). Os sinais elétricos emitidos pela célula de carga foram convertidos de sinais analógicos para digitais através de um amplificador (MCS1000VB marca EMG System do Brasil), usando um ganho de 300 vezes e uma excitação de voltagem de $5 \mathrm{~V}$ (volts). O sinal amplificado foi convertido em uma placa analógico-digital de aquisição de dados, amostrados a $100 \mathrm{~Hz}$ em software de aquisição e análise de dados Ariel Peformance Analysus System (APAS), e armazenados em um computador. Feedback visual em tempo real foi fornecido aos participantes por um osciloscópio analógico, modelo MINIPA - MO-1221S, de dois canais, com frequência de $20 \mathrm{MHz}$, sensibilidade máxima de $1 \mathrm{mV} / \mathrm{DIV}$ e tempo máximo de varredura de 20ns/DIV. O software Matlab 7.0 foi utilizado para análise das variáveis de interesse e o software Statistica 7.0 para as análises estatísticas.

Os participantes realizaram a tarefa de preensão em pinça sentados em uma cadeira e de frente para uma carteira escolar, de $73 \mathrm{~cm}$ de altura, na qual era posicionado o pedestal de ferro com a célula de carga em formato de pinça. O osciloscópio ficava a $50 \mathrm{~cm}$ dos participantes sobre outra mesa, juntamente com o amplificador de sinais e o computador que registrava os dados (Figura 1a).

\subsection{Procedimentos}

Ao chegar ao local de coleta de dados, os participantes eram solicitados a responder o Inventário de Preferência Manual de Edinburgh, para identificação da preferência manual. Em seguida, foram aferidos a estatura, o peso corporal e o comprimento da mão, correspondendo este à distância entre o médio estiloidal e o ponto mais distal do dedo médio, com a máo supinada e dedos estendidos (NORTON; OLDS; ALBERNAZ, 2005).

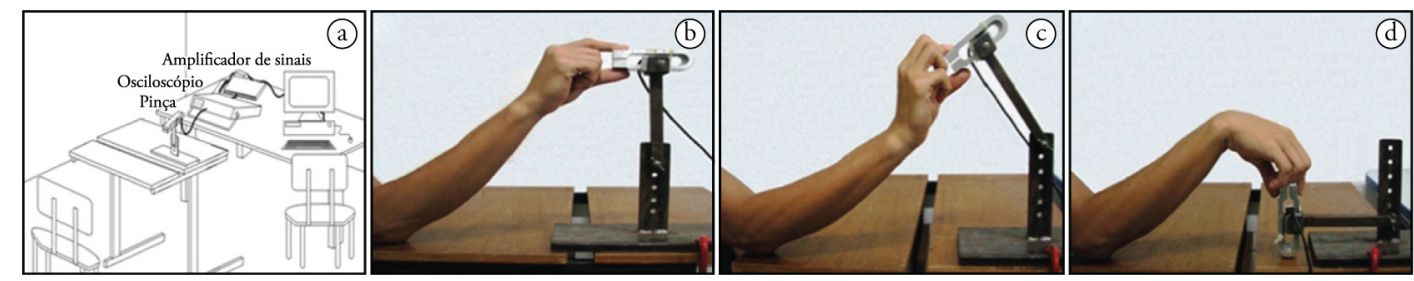

Figura 1. (a) Ilustração do ambiente de coleta de dados e disposição dos materiais, e posições articulares do punho: (b) neutral, (c) extensão e (d) flexão. 
A tarefa experimental consistia em produzir força isométrica de preensão em pinça em três posiçôes articulares do punho: (i) extensão do punho - ombro em aproximadamente $45^{\circ}$ de abdução e $45^{\circ}$ de flexão, cotovelo em $90^{\circ}$ de flexão, antebraço em pronação e punho em $40^{\circ}$ de extensão; (ii) flexão do punho - ombro em $45^{\circ}$ de abdução e $45^{\circ}$ de flexão, cotovelo em $75^{\circ}$ de flexão, antebraço em pronação e punho em $60^{\circ}$ de flexão, e (iii) neutra - ombro em $45^{\circ}$ de abdução e $45^{\circ}$ de flexão, cotovelo em $90^{\circ}$ de flexão, antebraço em pronaçáo e punho em $20^{\circ}$ de extensão (Figuras 1b, 1c e 1d).

Após a explicação da tarefa, o participante realizava duas tentativas de produção de força máxima por um período de três segundos, com descanso de um minuto entre estas, em cada posição articular do punho. O melhor resultado de produção de força máxima foi utilizado como parâmetro para cálculo das porcentagens de nível submáximo de força (i.e., $20 \%$ e $40 \%$ ) para as tentativas experimentais subsequentes. Em cada posição articular do punho, os participantes realizavam, com a mão direita, quatro tentativas de produção de $20 \%$ e quatro tentativas de produção de $40 \%$ da força máxima, sendo que a primeira tentativa de cada nível de produção de força foi utilizada para familiarização da tarefa e descartada das análises. Os participantes foram instruídos a encostar a linha de sua produção de força na "linha-alvo" (referente a $20 \%$ ou $40 \%$ da força máxima), ambas visíveis no osciloscópio (feedback em tempo real), e a manter a produçáo de força sob a "linha-alvo" durante dez segundos.

Os participantes ficavam sentados para executar a tarefa de preensão em pinça e mantinham o braço esquerdo descansando ao lado do corpo. Para iniciar cada tentativa, o experimentador dava um comando verbal “já!". Ao término da tentativa, o participante ouvia um bip e, então, parava de executar a tarefa e descansava o braço sobre a mesa. Em todas as posiçóes, o cotovelo direito permaneceu apoiado sobre a mesa. Foi fornecido descanso de 30 segundos entre tentativas. A coleta de dados foi realizada em aproximadamente 40 minutos por participante.

\subsection{Análise dos dados}

Os dados registrados, referentes à produção de força, foram filtrados com um filtro do tipo passa baixa Butherworth de segunda ordem, com frequência de corte de $25 \mathrm{~Hz}$, tendo sido os valores adquiridos em tensão (volts) convertidos para valores em força $(\mathrm{N})$, a partir de equaçóes obtidas no processo de calibração do dia do teste.
Para análise dos dados, foram consideradas apenas as três últimas tentativas de cada posição do punho em cada nível submáximo de produção de força. Os primeiros três segundos de cada tentativa não foram analisados de forma a excluir os ajustes iniciais de alcance aos níveis de força solicitados (i.e., 20\% e 40\%), sendo considerados somente para análise os sete segundos restantes de produção de força.

Para obtenção de medida de consistência das respostas de produção de força isométrica, foram calculados a média e o desvio padráo (DP) da força produzida em cada tentativa, para posterior cálculo do Coeficiente de Variação (CV), que é a razão entre o desvio padráo e a média de todos os dados (SCHMIDT; LEE, 1998): $C V=(D P / m e ́ d i a)$. Para análise da precisão nas respostas de produção de força isométrica, foram utilizadas duas medidas: Erro Absoluto (EA) e Erro Constante (EC). O Erro Absoluto é uma medida da precisão global de desempenho. É a média absoluta de desvio, sem considerar a direção de desvio do alvo. Já o Erro Constante é dado em unidades que representam a quantidade e a direção do desvio relativo ao alvo (SCHMIDT; LEE, 1998). No presente estudo, os EA e EC foram definidos como:

$$
\begin{aligned}
& \mathrm{EA}=\frac{\left(\sum\left|\mathrm{x}_{\mathrm{i}}-\mathrm{T}\right|\right)}{\mathrm{n}} \\
& \mathrm{EC}=\frac{\sum\left(\mathrm{x}_{\mathrm{i}}-\mathrm{T}\right)}{\mathrm{n}}
\end{aligned}
$$

Em que:

$T$ = nível submáximo de força estabelecido;

$x i=$ valores de força produzidos pelos participantes; $n=$ número de amostras da tentativa realizada.

\subsection{Tratamento estatístico}

Para analisar as diferenças na produção de força máxima entre homens e mulheres, e entre as diferentes posiçôes do punho, foi realizada Análise de Variância (ANOVA) 2 (Gênero) × 3 (Posição do punho) com medidas repetidas no último fator. Foi realizada Correlação de Pearson: entre (i) o peso corporal e a produção de força máxima, e entre (ii) o comprimento da mão e a produção de força máxima. Para analisar as diferenças no controle da produção de força submáxima dos dedos entre as posiçôes neutra, flexão e extensão do punho, foram realizadas ANOVAs: 3 (Posição do Punho) $\times 2$ (Nível de força), com medidas repetidas no último fator, para todas as variáveis dependentes (CV, EA e EC). Foi realizada Correlação de Pearson entre 
o peso corporal e o $\mathrm{CV}$, e entre o comprimento da mão e o $\mathrm{CV}$, nas tentativas de controle de produção de $20 \%$ e $40 \%$ da força máxima. Para detectar as diferenças nos fatores principais, foram feitos testes posteriores do tipo Tuckey HSD. O nível de significância adotado foi $p<0,05$.

\section{Resultados}

Primeiramente, os dados referentes às medidas antropométricas dos participantes estão apresentados na Tabela 1, seguidos dos resultados das análises estatísticas referentes à produção de força máxima em função do gênero e a correlação da mesma com peso corporal e comprimento da mão. Posteriormente, serão apresentados os resultados das análises estatísticas referentes a CV, EA e EC de produção de diferentes níveis de força, nas três posiçôes do punho, seguidos da correlaçáo do CV com o peso corporal e o comprimento da máo.

Produção de força máxima: Os resultados mostraram que os fatores Gênero e Posição do punho alcançaram nível de significância, sendo $F(1,19)=7,95, p<0,05$ e $F(2,38)=3,34, p<0,05$, respectivamente. No entanto, a interação entre estes fatores não alcançou nível de significância $(p>0,05)$. Os participantes do gênero masculino produziram força máxima significativamente maior do que participantes do gênero feminino $(\operatorname{masc}=57,6 \pm 12,7 \mathrm{~N} ;$ fem $=48,9 \pm 7,1 \mathrm{~N})$. Além disso, como mostra a Figura 2, independentemente do gênero, os participantes produziram força máxima maior na posição neutra, quando comparada com as forças nas demais posiçôes experimentais.

Correlaçáo entre peso corporal e produçáo de força máxima: Os resultados mostraram correlação positiva entre peso corporal e produção de força máxima de preensão isométrica em pinça na posição neutra $(r=0,71)$ e na posição de extensão do punho $(\mathrm{r}=0,60)$. Na posiçáo de flexáo do punho $(\mathrm{r}=0,07)$, tal correlação não alcançou nível de significância.

Correlaçáo entre comprimento da máo e produçáo de força máxima: Os resultados indicaram correlação positiva entre comprimento da mão e produção de força máxima de preensão isométrica em pinça, mas tal correlação não alcançou nível de significância em nenhuma das posiçóes do punho analisadas.

Coeficiente de variaçáo $(\mathrm{CV})$ : Análise de variância indicou que apenas o fator Nível de força alcançou nível de significância, $F(1,40)=15,3, p<0,001$. Em todas as posiçôes do punho, o CV foi menor na produção de $40 \%$ da força máxima $(4,1 \pm 1,1 \%)$ do que na produção $20 \%$ da força máxima $(5,2 \pm 1,3 \%)$.

Erro absoluto (EA): Análise de variância não indicou diferença significativa para nenhum dos fatores analisados e nenhuma interação entre eles $(p>0,05)$. De maneira geral, os participantes apresentaram EA semelhante em todas as posições do punho e níveis de força estudados.

Erro constante (EC): Análise de variância indicou que apenas o fator Nível de força alcançou significância, $F(1,40)=9,5, p<0,01$. Independentemente $\mathrm{da}$ posição do punho, o EC dos participantes foi maior na produção de $20 \%$ da força máxima $(0,55 \pm 1,28 \mathrm{~N})$ do que na produção de $40 \%$ da força máxima $(-0,38 \pm 1,59 \mathrm{~N})$.

Correlaçáo entre peso corporal e $\mathrm{CV}$ nas tentativas de produçáo de $\mathbf{2 0} \%$ e $\mathbf{4 0} \%$ da força máxima: Os resultados não indicaram correlação significativa entre peso corporal e CV na produção de $20 \%$ e $40 \%$ da força máxima em nenhuma das posiçóes do punho analisadas.

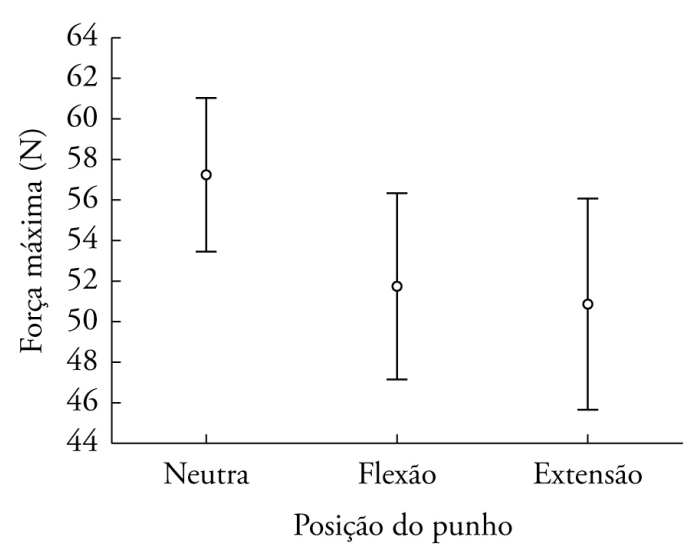

Figura 2. Produção de força máxima de preensão isométrica em pinça nas posições neutral, flexão e extensão do punho.

Tabela 1. Média e desvio padrão da idade, do peso corporal, da estatura e do comprimento da mão dos participantes de ambos os gêneros.

\begin{tabular}{lcccc}
\hline \multicolumn{1}{c}{ Gênero } & Idade (anos) & Peso corporal (Kg) & Estatura (cm) & Compr. Mão (cm) \\
\hline Homens $(\mathrm{n}=10)$ & $20,3 \pm 2,1$ & $79,4 \pm 16,4$ & $178,1 \pm 7,7$ & $18,5 \pm 0,9$ \\
Mulheres $(\mathrm{n}=11)$ & $22,5 \pm 2,3$ & $57,7 \pm 6,8$ & $164,8 \pm 7,0$ & $17,7 \pm 1,1$ \\
\hline
\end{tabular}


Correlaçáo entre comprimento da mão e CV nas tentativas de produçáo de $20 \%$ e $\mathbf{4 0} \%$ da força máxima: Os resultados indicaram correlação positiva, mas não significativa entre peso corporal e CV na produção de $20 \%$ e $40 \%$ da força máxima em nenhuma das posições do punho analisadas.

\section{Discussão}

Tendo em vista a revisão de literatura sobre a importância das atividades de preensão na vida diária e sobre a influência da posiçáo do membro superior nas mesmas, o objetivo do presente estudo foi analisar a influência da posição do punho na produção de força máxima e no controle de força submáxima dos dedos, quando da preensão em pinça polpa a polpa. Primeiramente, os resultados serão discutidos quanto à produção de força máxima na tarefa de preensão em pinça. Posteriormente, os resultados serão discutidos quanto ao controle de força submáxima na tarefa de preensão em pinça.

\subsection{Produção de força máxima na preensão em pinça}

Os resultados obtidos confirmam aqueles apresentados na literatura, que indicam que a força máxima produzida pelos dedos quando na posiçáo neutra do punho é maior do que nas posiçôes de extensão e de flexão desta articulação (CAREY; GALLWEY, 2002; IMRHAN, 1991; LI, 2002). A literatura específica da área de controle motor tem apontado a possibilidade de encurtamento e alongamento da musculatura dos dedos em posiçóes extremas de flexão e extensão do punho, prejudicando a produção de força máxima dos dedos em preensão em pinça. Esta relação comprimento-tensão dos músculos da mão é considerada ótima e confortável para a produção de força máxima dos dedos na posição neutra, de aproximadamente $20^{\circ}$ de extensão e $5^{\circ}$ de desvio ulnar (LOREN et al., 1996). Quando o punho assume posiçôes extremas de flexão e extensão, pode haver uma grande mudança na relação comprimento-tensão dos músculos que cruzam mais de uma articulação, como, por exemplos, os músculos flexor superficial dos dedos e flexor profundo dos dedos, que são os principais 'responsáveis' pela produção de força dos dedos (LI; ZATSIORSKY; LATASH, 2000). Desta forma, a produção de força máxima dos dedos em preensão em pinça é maior na posição neutra, pois a configuração das unidades motoras dos músculos responsáveis por essa ação se mantém preservada nesta posição. Além disso, nenhum dos participantes possuía histórico de qualquer patologia de membro superior, mas alguns relataram relativo desconforto na realização da tarefa experimental nas posições extensão e flexão do punho, em relação à posição neutra. Estes relatos sugerem que permanecer nestas posiçôes pode gerar ou agravar doenças articulares (ARAÚJO et al., 2002).

Além disso, no presente estudo, foi observado que os indivíduos do gênero masculino produzem, de modo consistente, mais força do que os indivíduos do gênero feminino em todas as posiçóes do punho estudadas. Estes resultados são consistentes com os apresentados na literatura (CAPORRINO et al., 1998; DEMPSEY; AYOUB, 1996). Isto pode ser devido a um maior uso dos músculos tênares (oponente do polegar, abdutor curto do polegar e o flexor curto do polegar) por indivíduos do gênero masculino durante as atividades esportivas e profissionais (DEMPSEY; AYOUB, 1996). De modo geral, estudos têm mostrado que a força máxima em pinça dos dedos de indivíduos do gênero feminino é de $65 \%$ a $79 \%$ da força máxima em pinça dos dedos de indivíduos do gênero masculino (HALLBECK; KAMAL; HARMON, 1992; HALLBECK; MCMULLIN, 1991, 1993). No presente estudo, a média da força máxima produzida pelos indivíduos do gênero feminino corresponde a $84,8 \%$ da média da força máxima produzida pelos indivíduos do gênero masculino, mostrando que as diferenças entre homens e mulheres, encontradas no presente estudo, foram menores do que as apontadas na literatura. Em suma, fica evidenciado que essas diferenças são dependentes das características das amostras estudadas e, portanto, a pesquisa nesta área requer considerar amostras maiores e a combinaçáo de resultados de diversos estudos.

Os resultados mostraram também correlação positiva entre peso corporal e capacidade de produção de força máxima em pinça pelos dedos na posição neutra e de extensão do punho. Ficou evidenciado que quanto maior o peso corporal, maior a produção de força máxima nestas posiçóes. Desta forma, se faz necessário considerar a variável 'peso corporal' em estudos que analisam a produção de força máxima. No entanto, essa variável é uma medida genérica da estrutura corporal, de modo que é importante averiguar o quanto a massa magra é representada no peso corporal. Desta forma, o presente estudo sugere que os parâmetros de produção de força sejam correlacionados com a porcentagem de massa magra do indivíduo. Assim, quando houver comparação da força máxima produzida entre diferentes grupos, é necessário fazer o pareamento dos mesmos de acordo com a relação 'massa magra e peso corporal', para que se evite a interferência desta variável nos resultados 
da produção de força máxima, especificamente, em preensão em pinça.

Não foi observada correlação positiva entre o comprimento da mão e a produção de força máxima em pinça no presente estudo. A literatura específica da área de controle motor aponta que medidas associadas ao tamanho e largura da máo são fortemente correlacionadas com a produção de força máxima em preensão palmar (NICOLAY; WALKER, 2005). Isso ocorre porque uma palma maior e mais larga sugere que esse indivíduo tem os músculos e ossos maiores, além de sugerir também vantagem em agarrar um dispositivo, como, por exemplo, um dinamômetro. No entanto, no presente estudo, a tarefa consistia em pressionar o dispositivo em forma de pinça apenas com os dedos, sem utilizar a preensão palmar. Por isso, o comprimento da mão não foi considerado medida preditiva da produção de força máxima pelos dedos.

\subsection{Controle de força submáxima na preensão em pinça}

Levando-se em consideraçáo os resultados do presente estudo no que diz respeito ao controle de $20 \%$ e $40 \%$ da força máxima produzida pelos dedos, ficou evidente que a posição do punho não interfere no controle de força submáxima na preensão em pinça. Tal resultado pode ser explicado por náo ter havido diferença significativa entre as posiçôes flexão, extensão e neutra do punho com relação às variáveis analisadas. No entanto, foi observado que o nível de força submáxima produzida pode interferir no controle de preensão em pinça. De maneira geral, ficou evidenciado que os participantes apresentaram maior dificuldade em controlar $20 \%$ da força máxima na preensão em pinça do que controlar $40 \%$ da mesma força em preensão em pinça, na tarefa do presente estudo. Uma explicação para tal resultado pode se apoiar no fato de que a variabilidade no controle da força em tarefas de preensão depende do nível de força produzido (MOERCHEN; LAZARUS; GRUBEN, 2007). Para explicar essa relação, o estudo de Slifkin e Newell (1999) requereu dos participantes que exercessem uma força de pressão digital isométrica em uma célula de carga, referente a 10, 20,30, 40, 50, 60, 7080,90 e $100 \%$ da força máxima produzida pelo dedo indicador. Os autores apresentaram dados de regularidade e variabilidade da força produzida em formato de $\mathrm{U}$, sendo que a performance era otimizada na região entre 30 e $40 \%$ da força máxima produzida.

Para esses autores, as forças-alvos mínimas e máximas são compreendidas como limites que restringem a dinâmica de produção de força. Especificamente, esses limites restringem os "graus de liberdade" disponíveis para configurar soluçôes flexíveis às demandas da tarefa. Na tarefa motora, os graus de liberdade, cujas configuraçôes são limitadas, são as unidades motoras. Entre 30 e $40 \%$ da força máxima produzida, a força é aumentada através do aumento do número de unidades motoras ativas. Porém, uma vez que todas as unidades motoras foram recrutadas, a geração de níveis maiores de força depende da modulação de frequência de descarga (KAMEN et al., 1995). Assim, em cerca de 30\% a $40 \%$ da produção de força máxima, as restrições impostas pelos limites mínimos e máximos da produção de força não estão atuando, e a força pode ser modificada usando uma ou ambas as estratégias de controle neural - recrutamento das unidades motoras e/ou modulação da frequência de descarga-, enquanto que, acima ou abaixo desta regiáo, apenas uma única estratégia pode ser utilizada.

No presente estudo, esse fenômeno foi observado devido ao coeficiente de variação e ao erro constante na tarefa de preensão em pinça terem sido maiores na condição de controle de $20 \%$ da força máxima do que na condição de controle de $40 \%$ da força máxima. Com base na discussão de Slifkin e Newell (1999) sobre a regiáo em que o desempenho é otimizado e tendo em vista que a posição do punho não interferiu no controle de níveis submáximos de força de preensão em pinça, os resultados do presente estudo sugerem que as unidades motoras necessárias para ajustes de parâmetros de força na tarefa de preensão em pinça não cruzam a articulação do punho, diferentemente daquelas utilizadas para a produção de força máxima nesta tarefa.

Além disso, os resultados do presente estudo também mostraram que não há correlação positiva entre peso corporal e coeficiente de variação da produção de $20 \%$ e $40 \%$ da força máxima, bem como não há correlação entre tamanho da mão e coeficiente de variação da produção de $20 \%$ e $40 \%$ da força máxima produzida pelos dedos em preensão em pinça. Estes resultados também podem ser discutidos em relaçáo às unidades motoras que controlam os ajustes de força presentes nos dedos que executam a tarefa. Sendo assim, as medidas de peso corporal e tamanho da mão não são preditivas do controle de força submáxima pelos dedos, na tarefa de preensão em pinça.

De maneira geral, muitos estudos focalizam a influência da posição do punho em tarefas de preensão em pinça; entretanto, esses estudos utilizam para tal fim diferentes posturas do membro superior e apenas a variável produção de força máxima para fins de 
análise. Estes fatores diminuem a possibilidade de uma comparação objetiva dos resultados do presente estudo com a literatura da área, ao mesmo tempo em que mostram quão vastas são as possibilidades de ação das mãos e dos dedos. Neste sentido, consideramos que estudos objetivos seriam importantes para embasar os processos de reabilitação motora, uma vez que as posiçóes do punho e do membro superior durante os exercícios de cinesioterapia (Fisioterapia e Terapia Ocupacional) influenciam de maneira considerável a produção de força.

\section{Considerações finais}

Este estudo verificou a influência da posição do punho na produção de força em preensão em pinça. Embora a produçáo de força pelos dedos tenha sido foco de um grande número de estudos acadêmicos, pouco se sabe sobre o controle de níveis de força submáximos a partir de dados na tarefa de preensão em pinça e qual a influência da posiçấo do punho na mesma. O presente estudo mostrou que a posiçáo do punho e o peso corporal interferem na produçáo de força máxima, mas não interferem no controle de níveis de força submáximos dos dedos na tarefa de preensão em pinça. A forma de preensão em pinça responde por um grande número de atividades que requerem precisão no controle do objeto na atividade realizada e, por isso, se faz necessário o desenvolvimento de estudos objetivos na investigação da posição das diferentes articulaçóes envolvidas na execução da mesma.

\section{Referências}

ARAÚJO, M. P. D. et al. Estudo populacional das forças das pinças polpa-a-polpa, trípode e lateral. Revista Brasileira de Ortopedia, São Paulo, v. 37, n. 11-12, p. 496-504, 2002.

CAPORRINO, F. A. et al. Estudo populacional da força de preensäo palmar com dinamômetro Jamar. Revista Brasileira de Ortopedia, Sáo Paulo, v. 33, n. 2, p. 150154, 1998.

CAREY, E. S. J.; GALLWEY, T. J. Effects of wrist posture, pace and exertion on discomfort. International Journal of Industrial Ergonomics, Clemson, v. 29, n. 2, p. 85-94, 2002. http://dx.doi.org/10.1016/S01698141(01)00053-1.

DEMPSEY, P. G.; AYOUB, M. M. The influence of gender, grasp type, pinch width and wrist position on sustained pinch strength. International Journal of Industrial Ergonomics, Clemson, v. 17, n. 3, p. 259-273, 1996. http://dx.doi.org/10.1016/0169-8141(94)00108-1.
FELDMAN, R. Functional anatomy of the upper limb. In: KUMAR, S. Biomechanics in ergonomics. Kingston: Taylor \& Francis, 1999. p. 89-95.

FRANKEL, V. H.; NORDIN, M. Biomecânica básica do sistema músculo esquelético. Rio de Janeiro: Guanabara Koogan, 2003.

FREITAS, P.; KRISHNAN, V.; JARIC, S. Force coordination in object manipulation. Journal of Human Kinetics, Mikolowska, v. 20, n. 1, p. 37-50, 2008. http:// dx.doi.org/10.2478/v10078-008-0016-8.

FULLER, Y.; TROMBLY, C. A. Effects of object characteristics on female grasp patterns. The American Journal of Occupational Therapy, Boston, v. 51, n. 7, p. 481487, 1997. http://dx.doi.org/10.5014/ajot.51.7.481. PMid:9242853.

HALLBECK, M. S.; MCMULLIN, D. L. Effect of gloves, wrist position, and age on peak three-jaw chuck pinch force: a pilot study. In: PROCEEDINGS OF THE HUMAN FACTORS SOCIETY, 35., 1991, Santa Monica. Anais... Santa Monica: Human Factors Society, 1991. p. 753-757.

HALLBECK, M. S.; KAMAL, A. H.; HARMON, P. E. Effects of forearm posture, wrist posture, gender, and hand on three peak pinch force types. In: PROCEEDINGS OF THE HUMAN FACTORS SOCIETY, 36., 1992, Santa Monica. Anais... Santa Monica: Human Factors Society, 1992. p. 801-805.

HALLBECK, M. S.; MCMULLIN, D. L. Maximal power grasp and three-jaw chuck pinch force as a function of wrist position, age, and glove type. International Journal of Industrial Ergonomics, Clemson, v. 11, n. 3, p. 195-206, 1993. http://dx.doi.org/10.1016/0169-8141(93)90108-P.

IMRHAN, S. N. The influence of wrist position on different types of pinch strength. Applied Ergonomics, Amsterdam, v. 22, n. 6, p. 379-384, 1991. http://dx.doi.org/10.1016/0003-6870(91)90079-W. PMid:15676836.

JOSTY, I. C. et al. Grip and pinch strength variations in different types of workers. The Journal of Hand Surgery, California, v. 22, n. 2, p. 266-269, 1997. http://dx.doi. org/10.1016/S0266-7681(97)80079-4. PMid:9150004.

KAMEN, G. et al. Motor unit discharge behavior in older adults during maximal-effort contractions. Journal of Applied Physiology, Bethesda, v. 79, n. 6, p. 1908-1913, 1995.

LAMOREAUX, L.; HOFFER, M. M. The effect of wrist deviation on grip and pinch strength. Clinical Orthopaedics and Related Research, Philadelphia, v. 314, p. 152-155, 1997.

LI, Z. M. The influence of wrist position on individual finger forces during forceful grip. Journal of Hand Surgery, Chicago, v. 27, n. 5, p. 886-896, 2002. http://dx.doi. org/10.1053/jhsu.2002.35078. PMid:12239681. 
LI, Z. M.; ZATSIORSKY, V. M.; LATASH, M. L. Contribution of the extrinsic and intrinsic hand muscles to the moments in finger joints. Clinical Biomechanics, Philadelphia, v. 15, n. 3, p. 203-211, 2000. http://dx.doi.org/10.1016/S0268-0033(99)00058-3. PMid:10656982.

LIMA, K. C. D. A.; FRANCISCO, M. M.; FREITAS, P. B. D. Relationship among performance in different tests often used for hand function assessment. Fisioterapia em Movimento, Curitiba, v. 25, n. 3, p. 517, 2012. http:// dx.doi.org/10.1590/S0103-51502012000300007.

LOREN, G. J. et al. Human wrist motors: biomechanical design and application to tendon transfers. Journal of Biomechanics, Philadelphia, v. 29, n. 3, p. 331-342, 1996. http://dx.doi.org/10.1016/0021-9290(95)00055-0. PMid:8850639.

MATSUSHITA, N. et al. Electromyogram analysis and electrical stimulation control of paralysed wrist and hand. Journal of Electromyography and Kinesiology, Philadelphia, v. 5, n. 2, p. 117-128, 1995. http://dx.doi.org/10.1016/1050-6411(95)00001-G. PMid:20719643.

MOERCHEN, V.; LAZARUS, J.; GRUBEN, K. Task-dependent organization of pinch grip forces. Experimental Brain Research, Berlin, v. 180, n. 2, p. 367-376, 2007. http://dx.doi.org/10.1007/s00221-007-0864-9. PMid:17554577.

MOGK, J.; KEIR, P. The effects of posture on forearm muscle loading during gripping. Applied Ergonomics, Amsterdam, v. 46, n. 9, p. 956-975, 2003. http://dx.doi.org/10.1080/0014013031000107595. PMid:12775491.
NAPIER, J. A mão do homem: anatomia, função, evolução. Rio de Janeiro: Zahar, 1983.

NEWELL, K. M. et al. Body scale and the development of prehension. Developmental Psychobiology, Malden, v. 22, n. 1, p. 1-13, 1989. http://dx.doi.org/10.1002/ dev.420220102. PMid:2912811.

NICOLAY, C. W.; WALKER, A. L. Grip strength and endurance: Influences of anthropometric variation, hand dominance, and gender. International Journal of Industrial Ergonomics, Clemson, v. 35, n. 7, p. 605-618, 2005. http://dx.doi.org/10.1016/j.ergon.2005.01.007.

NORTON, K.; OLDS, T.; ALBERNAZ, N. M. F. D. Antropométrica: um livro sobre medidas corporais para o esporte e cursos da área de saúde. Porto Alegre: ArtMed, 2005.

OLDFIELD, R. C. The assessment and analysis of handedness: the Edinburgh inventory. Neuropsychologia, Dallas, v. 9, n. 1, p. 97-113, 1971. http://dx.doi. org/10.1016/0028-3932(71)90067-4.

SCHMIDT, R. A.; LEE, T. D. Motor control and learning: a behavioral emphasis. Champaign: Human Kinetics, 1998.

SLIFKIN, A. B.; NEWELL, K. M. Noise, information transmission, and force variability. Journal of Experimental Psychology: Human Perception and Performance, Vancouver, v. 25, n. 3, p. 837-851, 1999. http://dx.doi. org/10.1037/0096-1523.25.3.837. PMid:10385989.

ZATSIORSKY, V. M.; LI, Z. M.; LATASH, M. L. Enslaving effects in multi-finger force production. Experimental Brain Research, Berlin, v. 131, n. 2, p. $187-$ 195, 2000. http://dx.doi.org/10.1007/s002219900261. PMid:10766271.

\section{Contribuição dos Autores}

Vanessa Luzia Barros de Andrade, Cynthia Yukiko Hiraga e Ana Maria Pellegrini participaram na concepçáo do projeto, coleta e análise dos dados e redação do texto. Marcela de Castro Ferracioli e Adriane Guzman Pasculli participaram na análise dos dados, redação do texto e revisão. Todos os autores aprovaram a versão final do texto. 